with cold sweat, bowels not moved, and no escape of gas, stomach unable to retain anything whatever, pain and tenderness in the spot already mentioned still present, and tenderness over a somewhat increased area three or four inches in diameter, temperature $98^{\circ}$ pulse 110-120. The patient echoed my own conviction when he said " Doctor, I can't stand it much longer." I explained to him and his family my opinion of the case, that he had occlusion of the bowels, that from appearances the end seemed near, and $I$ suggested an operation as his only chance of recovery. They consented, and I immediately called Dr. John C. Irish, of Lowell, who concurred in my diagnosis, and at noon on Thursday the 24th, he performed laparotomy in the presence of Drs. Bradt and Hoar of Lowell, and myself.

The patient being under ether the abdomen was opened in the median line by an incision seven inches long, reaching from the umbilicus to the pubes. Owing to the tense condition of the recti muscles, the incision was extended an inch above the umbilicus, and the left rectus muscle was divided at the left of the umbilicus.

We could learn nothing from inspection with the bowels in situ, on account of the extreme distension of the intestines from accumulated gas; nor could anything be ascertained by sense of touch with the hand in the abdominal cavity. . Therefore the intestines were rapidly but carefully drawn out until about fifteen feet of them lay upon the abdomen, when sharp resistance was felt and the increased congestion of the intestines showed the constriction was reached. Dr. Irish then passed his hand into the abdominal cavity and withdrew the invaginated portion and relieved the obstruction.

At the location of the intussusception, which was ileo-coecal, the bowel was intensely congested and somewhat darkened in hue. The invaginated portion, about three inches in length, was thickly studded with deposits of lymph. The congestion extended up the ilium only a few inches above the obstruction. The remainder of the small intestine appeared to be free from any inflammatory action. It was, however, greatly distended with gas, and in the lower portion of the ileum near the site of the invagination the distension had become very great. The colon was free from congestion and flaccid.

Up to this time the bowels outside the abdomen had lain perfectly quiet and dormant; but when the constriction was relieved, there was a sudden rush of gas and the peristaltic action of the intestines started up, and gas escaped from the anus together with a large, thin, feculent, discharge. The intestines were replaced with comparative ease, and the incision closed with silk sutures and adhesive straps. There was profound shock during the manipulation of the bowels, though the time of exposure was not more than five minutes. Our hands were washed in a five per cent solution of carbolic acid, and the instruments and sponges were immersed in a solution of the same strength.

Patient rallied well and quickly from the operation, and was given a hypodermic injection of morphine, one sixth grain every five or six hours for three days, and rectal injections of three ounces milk and half ounce brandy, every three hours. Gas was passed freely, and the bowels moved spontaneously on the fourth day. Temperature on evening of third day was $101^{\circ}$, at no other time did it rise above $100^{\circ}$. After the third day the injections of milk and brandy were discontinued and he was fed by the mouth, with milk, beef-tea, custards, and eggs. The wound healed throughout by primary union. Stitches were removed on eighth and ninth days, and patient sat up on fourteenth day.

In this case the following points are of interest: -

(1) The persistent and localized pain at the seat of obstruction, and the absence of any tumor at that point.

(2) The length of the incision. Some authors advise an incision only two or three inches in length. When we consider that shock is the most formidable factor in these cases, and that it begins the moment the manipulations of the bowel commence, and continues until the intestines are replaced, it seems to me that the long incision is far preferable to a short one. With the former you have the additional room to work in, and the reposition of bowels is much more easily offected.

(3) The agitation and peristaltic action of the intestines as they lay upon the abdomen, and the evacuation of the bowels and escape of gas immediately following the relief of the constriction.

I am indebted to Dr. Irish for the following summary of cases reported, where the operation was deliberately undertaken for occlusion of the bowels by invagination, volvulus, or constricting bands : -

$$
\begin{aligned}
& \text { Whole number of cases . } \\
& \text { Adults } \\
& \text { Deaths } \\
& \text { Recoverie } \\
& \text { Children } \\
& \text { Deaths } \\
& \text { Recoveries . }
\end{aligned}
$$

Two cases not stated whether adults or children deaths.

This table would indicate that the operation is more favorable in children than adults, probably from the fact that the obstruction in children is more likely to be of a very acute character, is more promptly diagnosticated, and the operation made in a short time after very grave symptoms have declared themselves. The detailed reports of several of the above cases of adults, show that the operation was deferred until it was indeed an operation of last resort of very desperate character.

Recoveries are distributed geographically, as follows : -

Adults - France 1, England 2, Scotland 1.

Children - America 1, England 2.

Cause of death, in five cases, shock, a few hours after the operation.

The above summary is as complete as the resources within our reach allowed us to make. It would appear from this that the case I have described is the first successful case of laparotomy for intestinal obstruction in an adult, that has been reported in this country.

\section{TREATMENT OF ABORTION, WITH CASES. ${ }^{1}$}

$$
\text { BY J. L. SULLIVAX, M.D., OF MALDEN. }
$$

THE proper treatment of abortion, or, strictly speaking, of some of the conditions which attend abortion, is still an open question. That the existing antagonism of opinion and method is fostered by no dearth of interest in the subject, or of ability enlisted in its discussions, a glance at current medical literature will confirm. Nor is the disagreement occasioned by any scarcity of clinical opportunities. We live in a period of prevailing foeticide.

1 Read at the Obstetrical Section of the Suffolk District Medical Society, March 18, 1885. 
Rather is it due, I believe, to the unavoidable circumstance that the field of obstetric practice in this direction is broad and stretches beyond the horizon of individual experience. Ars longa, vita brevis.

According to recent estimates the proportion of abortions and miscarriages to deliveries at term is not less than one to three; in other words, of all impregnated ova in the human female at least twenty-five per cent perish in immaturity, compelling, on the part of the woman concerned, no small sacrifice of health and sometimes of life.

Where interests of such magnitude and importance are involved, the settlement of any doubtful or controverted point is a desideratum, and any observations which tend to this result will be regarded, I trust, as not unworthy of attention.

In the condition known as incomplete abortion, three distinct methods of treatment have been adopted :-

(1) The radical method, championed by distinguished obstetricians, that is, the immediate evacuation of the contents of the uterine cavity.

(2) The expectant method, pursued by perhaps the majority of physicians, that is, the plan of patient waiting for nature to effect the expulsion of the product of conception, the physician interfering only when the patient's life or health is threatened, or when the natural powers seem inadequate to their task.

(3) Nihilism, or the let-alone, or do-absolutelynothing plan, which differs from the expectant method in this, it forbears to invade the uterine cavity. The physician, who chooses this method, while combating symptoms as they arise, so far leaves the case to itself, that he relies for the extrusion of the ovum or decidua on the unassisted powers of the female economy. Probably few physicians take this course to-day, but the list would include some able men.

It is of the last, or let-alone plan, that I shall speak to-night.

How widely a belief in absolute non-interference with the cavity of the aborting uterus prevails amongst physicians in this State, and how consistently in the emergencies of actual practice the plan is carried out by those who advocate it on theoretical grounds, I have no means of determining. I presume, however, that during the period which preceded the discovery of anæsthesia, the birth of modern gynæcology and the use of antiseptics, the let-alone method was much more frequently employed than it now is. That it is no mere relic of fossilized conservatism, or, if you please, no mere fragment of adipocere from some long defunct corpus medicina, will appear from the fact that only two years ago my attention was strongly directed to the subject in consequence of a statement made by a distinguished Fellow of this Society at one of its District Meetings, where the treatment of abortion and miscarriage formed the topic of discussion. The gentleman to whom I refer, said that on reviewing his forty years' experience in midwifery he could recall no case of incomplete abortion, or of premature labor, which had required any operative procedure for the delivery of the secundines, etc. Retention of a dead ovum or a portion of placenta had occurred as frequently in his practice as in that of his neighbors, and for the evacuation of the contents of the womb he had uniformly relied upon the unaided efforts of nature, and his patients had invariably recovered. This testimony to the triumph of the conservative principle in the management of these cases, emanating, as it did, from an experienced and thoroughly trustworthy source, struck me as entitled to serious consideration, and I asked myself the question, how shall we interpret the extraordinary success of this method, exemplified, as it is, not in the favorable termination of a single critical case, but in an unbroken series of cases extending through many years. Shall we regard this result as an instance of unparalled good fortune, or as an expression of an important truth not hitherto fully recognized, that aborting women, so far as the extrusion of the uterine contents is concerned, if left to the kindly offices of nature, do well. Ought not this protracted experience to serve as a lesson and a rebuke to those amongst us whose treatment in similar cases is more or less heroic?

Finding myself unable to answer this inquiry from any data at my command, I resolved to test the letalone treatment of incomplete abortion in my own practice, as far as this could be done without compromising the health or lives of the patients. What follows, then, is the record of a conscientious effort to deter mine the practical value, or otherwise, in certain criti cal obstetric conditions, of the vis medicatrix natura. Six aborting women became, in turn, the unwitting subjects of this quasi-therapeutical experiment, which ended with the sixth case, my object being then accomplished. The interest lent these cases not otherwise remarkable in themselves (with perhaps one exception) by the special investigations to which they were made to contribute, is my apology for asking the attention of the Section to the salient points of each.

CAse I. Mrs. S., aged forty-two years, American, multipara, aborted for the third time October 13, 1883 , being then three months and a half advanced in her seventh pregnancy. On my arrival I found the fotus already expelled, the placenta retained and partially attached, the closed condition of the os and cervix uteri precluding the possibility of its extraction without the previous use of tents. The woman was steadily losing blood in quantity not immediately alarming but too profuse to go on unchecked. I therefore plugged the os and tamponed the vagina thoroughly, a la Simpson, with strips of cotton cloth. The plug and tampon remained in situ twenty-four hours and were then replaced by others which were left for the same length of time. Meanwhile considerable sero-sanguineous discharge oozed through the cloth and the patient grew sensibly weaker. Failing in a third and last attempt to fully control the bleeding by means of the tampon, I yielded to the patient's entreaties, dilated the cervix with sponge tents, and extracted the contents of the uterns, under ether. Mrs. S. made a good though tedious recovery, the debility and anæmia consequent on the abortion, and aggravated, perhaps, by delay in resorting to radical treatment, persisted for several months.

CASE II. Mrs. M., American, aged twenty-four years, a perfectly healthy married woman in good circumstances, when four and one-half months pregnant with her second child, was taken January 2, 1884, with slight flowing, unattended with pain. On discovering her situation the lady sent for me. On my arrival she was ordered to take the bed. 'The usual measures for the prevention of abortion were tried but proved unavailing. Four days later travail pains began, and she soon gave birth to the foetus. Thereupon the womb contracted firmly on the undetached placenta and all hæmorrhage ceased. No ergot was given. 
During the succeeding four days the situation continued unchanged. There was no pain and absolutely no vaginal discharge. Her napkins were removed unsoiled and no trace of blood appeared on the examining finger. Meanwhile the umbilical cord separated from its placental attachment and came away but the womb remained closed. The morning of the fifth day was ushered in with pains, which caused the womb to dilate. 'The afterbirth could now be felt, lying high up and firmly attached - throughout its whole extent - to the uterine wall. A slight sanguineous discharge, less than occurs in scanty menstruation, now set in. Five days afterwards, the status quo continuing, and the lady's husband refusing to sanction any further dalliance with the case, I etherized the patient and with some difficulty removed the still firmly adherent placenta. No unpleasant symptoms followed, and Mrs. M. rapidly regained her usual excellent health.

Case III. Mrs. W., aged thirty years, multipara, a healthy, hard-worked American female, wife of a respectable and well-to-do mechanic, determined to cut short her third pregnancy. By means unknown to the writer the ovum perished at two and a half months. Notwithstanding a constant, fetid vaginal discharge, Mrs. W. attended to her household duties and exercised more than usual out of doors. When this state of affairs had lasted a fortnight a sudden rush of blood from the vagina caused Mrs. W. to fall swooning on the kitchen floor. On reaching the spot on the evening of August 3, 1884, I found the woman in a condition of partial unconsciousness and well-nigh fatal exhaustion. A pool of coagulating blood marked the place where she had fallen; the bed to which she had been conveyed was swimming in blood, blood was still streaming from the vulva as fast as the failing circulation would allow. Not a moment was to be lost. Baring my arm and hastily thrusting it into the vagina, which was relaxed, I succeeded in removing a putrid mass from the cavity of the womb, when fortunately for both patient and physician the flaccid organ contracted and the bleeding ceased. Mrs. W. slowly rallied, but she is still feeble and an anæmic to a sad degree. The value of this experiment is not lessened by the fact that it was tried by the patient herself.

CASE IV. Mrs. E., multipara, aged thirty-two years, a healthy, hard-working Irish woman, four and one half months advanced in her fifth pregnancy, aborted for the second time on the morning of September 9,1884 . I was not present at the delivery, but the attending physician on leaving the house, to use the patient's words, pronounced her " all right." There were several by-standers, none of whom had seen the afterbirth, and I was sent for to ascertain if the delivery had been completed. Examination disclosed a state of tetanic uterine contraction, and I learned that ergot had been given. Feeling confident that the cavity of the enlarged and globular womb contained a portion of the product of conception, I enjoined absolute rest in bed, and explained to the patient the necessity of obedience. A week later Mrs. E. was assailed with sudden and copious flooding, which ceased only on her becoming faint. On four succeeding occasions, at intervals of several days the bleeding returned. The patient daily grew weaker, and presented a striking picture of progressive anæmia. Convinced of the uselessness, if not wickedness, of longer delay, I dilated the still strongly contracted cervix with several successive tents, and October 12, 1884, removed from the left corner of the womb a portion of placenta. A sharp attack of metro-peritonitis, ushered in by rigors, high temperature and rapid pulse kept the patient's life in jeopardy for several weeks. Her health is still poor.

Case V. Mrs. K., a young, newly-married American girl, wife of a well-to-do mechanic, for the first time pregnant, succeeded in causing the death of the ovum at two and a half months. I saw her April 4, 1884 ; she was about doing house work, but complained of feeling ill, and of an offensive vaginal discharge. Ascertaining that the womb contained a putrescent ovum, and that the cervix was elongated and brawny, I sent the patient to bed where she remained for two weeks without any marked change in the symptoms. A severe chill followed by abdominal tenderness and fever caused her to summon me for the second visit on the 18th. Dilation of the cervix by a succession of tents was finally accomplished, and the uterine contents extracted on the 25th. A long and severe attack of pelvic-peritonitis, from which Mrs. K. has not yet fully recovered, completes the outline of the case.

Case VI. Miss A., aged twenty-two, American, unmarried, a mill-operative, with whose previous history I am unacquainted, began to menstruate as usual on September 20, 1884. On the 9th of October she had sexual intercourse. The catamenia due October 18th, failing to appear, she consulted a doctor, who prescribed some pills, but according to her account, did nothing more. November 19th she was taken with pains and flowing, and passed per vaginam several small coagula and fragments of a mutilated ovun, which were preserved for my inspection. On the next day I was sent for and found her in bed, free from pains and flowing, womb enlarged, os slightly patulous and soft. Enjoining rest in bed until abortion terminated, and giving suitable directions concerning diet, etc., I left with the understanding that $I$ was to be sent for when any new symptoms appeared. The subsequent history is as follows: patient kept her bed one week, then wearying of the confinement and feeling quite well, she got up, went about the house and ventured out of doors for several short walks. Thursday, December 18th, having decided to go "down East", next day, she spent several hours in packing her trunk. Just as the work was finished she was seized with excruciating pains in the hypogastrium, became collapsed and died within an hour. She was breathing her last when I reached the bedside. No autopsy was permitted, but a careful examination of the abdomen and pelvic cavity by conjoined manipulations satisfied me that death had been caused by internal hæmorrhage. Not a drop of blood escaped from the os uteri. With the fatal termination of this case I abandoned the conservative treatment of incomplete abortion.

The foregoing history leads to the conclusion that an early resort to radical measures was indicated in each case and might possibly have saved a life.

The contrast between the outcome of these abortions and the success achieved by our colleague emphasizes again the familiar, but ever instructive lesson, namely : Of the great circle of collective medical experience how small an arc is that which the practice of any one man subtends! 